\title{
Development and Utilization of New Diagnostics for Dense- Phase Pneumatic Transport
}

Quarterly Technical Progress Report (April 1, 1991 to June 30, 1991)

Contract number: DE-AC22-88PC88947

Contract Period of Performance: October 1, 1988 to September 30, 1991

Contractor: Cornell University, Ithaca, NY 14853

$\mathrm{DOE} / \mathrm{PC} / 88947--\mathrm{Tll}$

Contract Participants: Michel Y. Louge, James T. Jenkins

DOE Project Manager: Mehrdad C. Massoudi

LE92 000337

US/DOE patent clearance is not required prior to the publication of this document.

\section{Summary of accomplishments}

Dense-phase pneumatic transport is an attractive means of conveying solids. Unfortunately, because of the high solid concentrations, this transport method is a difficult regime in which to carry out detailed measurements. Hence most details of the flow are unknown.

In this context, the main objective of this work is to develop probes for local measurements of solid velocity and holdup in dense gas-solid flows. In particular, we have designed capacitance probes to measure local, time-dependent particle concentrations, and a new optical fiber probe based on laser-induced-phosphorescence to measure particle velocities. We have described the principle of the capacitance diagnostic in [Particulate Science \& Tech., $751: 59$ (1989)] and its calibration in [Powder Tech. 62, 85-94 (1990)]. In addition, we have recently published data on the optical anemometer in [Applied Optics 30, 1976-81 (1991)].

Because we anticipate that recent theories of rapid granular flows will bring insight to the dense pneumatic transport of particles, we have sought to substantiate these theories through computer simulations. There we have verified the theory of Hanes, Jenkins \& Richman (1988) for the rapid, steady shear flow of identical, smooth, nearly elastic disks; driven by identical, parallel, bumpy boundaries [Phys. Fluids A 2 (6), 1042-44 (1990)]. Also, in examining the theory of Jenkins \& Richman (1988) for the rapid flows of uniform smooth inelastic disks under simple shear, we have revealed the formation of microstructures there [Phys. Fluids $A \mathbf{3}$ (1), $47-57$ (1991)]. Finally, because granular flows depend strongly on the nature of their interaction with a boundary, we have verified the boundary conditions calculated by Jenkins (1991) for spheres interacting with a flat,

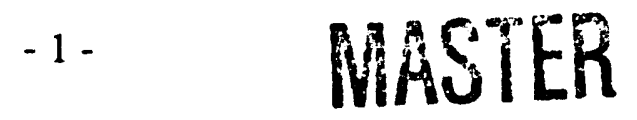


frictional surface [Proc. ASCE Eng. Mech. Conf., Columbus, OH, May 1991]. During the previous reporting period, we began a study of the time relaxation of the second moment of velocity fluctuations for a collection of disks undergoing simple shear.

In the present reporting period, we have completed this study of relaxation by comparing results of simulations with the theoretical predictions of Jenkins and Richman (1988). These results will appear in the Proceedings of the $2^{\text {nd }}$ US/Japan Conference on Micromechanics of Granular Materials (enclosed). In addition, we have concluded a series of experiments with flour plugs in the dense-phase pneumatic setup. These experiments will be interpreted in the next reporting period. Finally, we have established several industrial contacts to transfer the diagnostic techniques developed under this contract.

\section{Progress Report}

\section{1) Relaxation of the second moments in rapid shear flows of smooth disks}

Because granular flows such as pneumatic conveying are inherently unsteady, it is important to investigate how long it takes for a collection of particles to relax to the state predicted by steady granular theories. We have employed an algorithm described in the previous quarterly report to simulate the relaxing flows. As the attached paper indicates (Louge, Jenkins \& Hopkins, 1991), for nearly elastic disks the time-history of the relaxation is in excellent agreement with the theory of Jenkins and Richman (1988) in both its dense and dilute limits. However, deviations are observed in the case of inelastic particles.

\section{2) Experiments in dense-phase pneumatic transport}

During the present reporting period, we have completed a series of experiments with the dense-phase pneumatic setup. There we have studied the flow behavior of distinct flour plugs of various length in a vertical glass tube of $2.18 \mathrm{~cm}$ ID. In these experiments we have recorded the plug velocity, the gas velocity and the pressure across the plug using a video monitor, a rotameter, and a differential pressure transducer, respectively. To ensure reproducibility between runs, the carrier gas was supplied by a bottle of dry nitrogen, and the flour was carefully dried by fluidizing it in situ before each run. After fluidization, the: flour was left to pack loosely as a solid plug.

Figure 1 compares the gas and plug velocities. This plot suggests that the plug moves at nearly the same velocity than that of the gas. Because the two velocities were recorded with different instruments, it is difficult to establish the velocities difference with 
velocity. Here it appears that pressure drop is a linear function of velocity, and that it is proportional to plug length (Fig. 3).

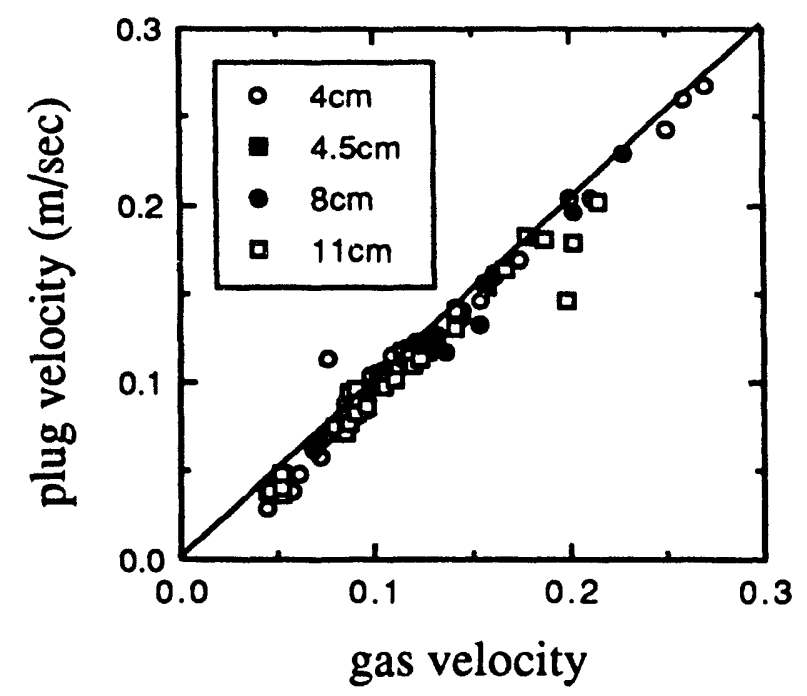

Fig. 1. Comparison of plug and gas velocities. The different symbols represent plug lengths shown in the legend.

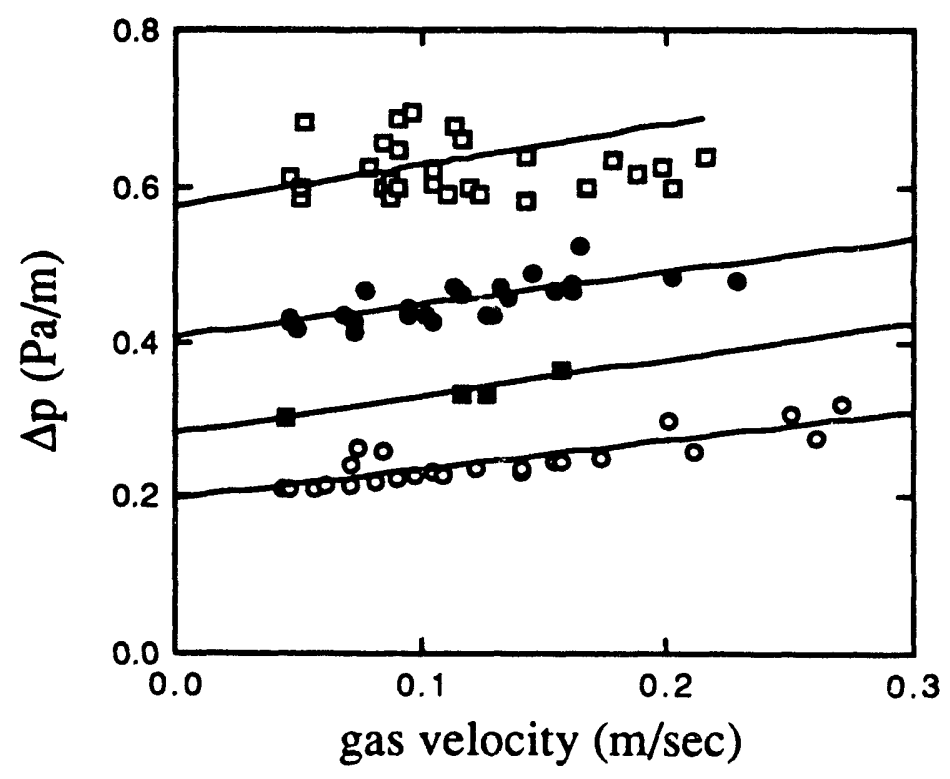

Eig. 2. Pressure drop across plugs vs. gas velocity. See the legend of Fig. 1 for symbolis. 


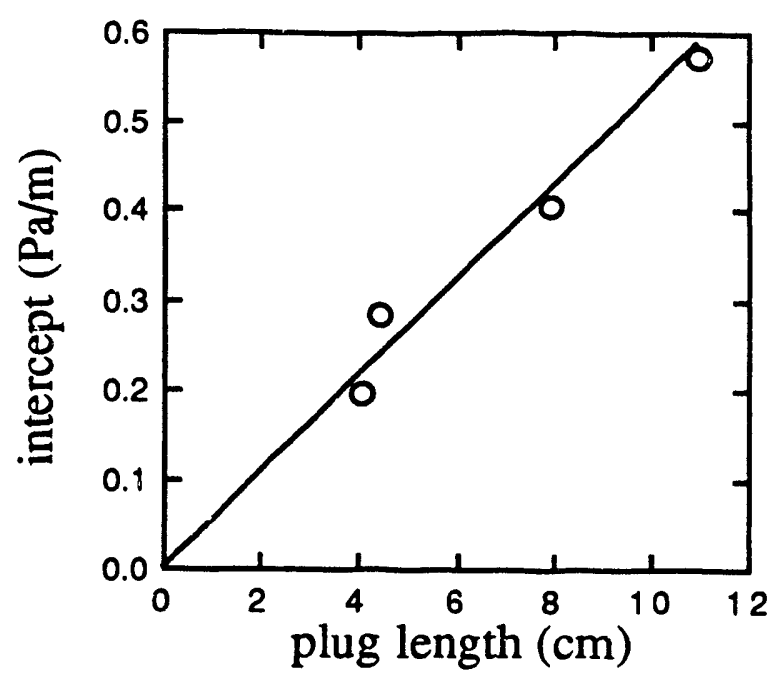

Fig. 3. Intercept of the best fits of Fig. $3 v s$. plug length. The line is a best fit to the data.

This data suggests a simple force balance over the entire plug, as follows

$\frac{P}{A}\left(\tau_{g}+\tau_{p}\right)+\rho_{p}(1-\varepsilon) g=\frac{\Delta p}{L}$,

where $P$ and $A$ are the inner perimeter and cross-section of the pipe, respectively; $\tau_{g}$ and $\tau_{p}$ are the stresses exerted by the gas and the particles on the pipe wall; $\rho_{p}(1-\varepsilon)$ is the bulk density of the particles, $g$ is the acceleration of gravity; and $\Delta p$ is the pressure drop across the plug of length $L$. The apparent linear increase of $\Delta p$ with gas velocity may be the result of viscous dissipation at the wall through the gas shear stress $\tau_{\mathrm{g}}$.

\section{3) Transfer of know-how}

Since the beginning of this project, we have sought to transfer the diagnostic techniques developed here to industry and other universities. In this context, we are happy to report that considerable attention has been drawn to the capacitance and optical diagnostics. Despite the fact that these probes are now public (and likely not patentable), other parties have sought our advice to develop similar probes for industrial environments. Two major US oil companies, a leading firm in filter technology, a US boiler manufacturer, several universities and two companies involved with capacitance measurements have shown continued interest and/or initiated new projects around these ideas. In particular, we have helped one company develop a hot version of our capacitance "traversing" probe for use in circulating fluidized bed coal combustors. 


\section{References}

Hanes, Jenkins \& Richman : J. Applied Mech. 55, 969 (1988).

J.T. Jenkins: "Boundary Conditions for Rapid Granular Flows: Flat, Frictional Walls", J. Appl. Mech., in press (1991).

Jenkins \& Richman: J. of Fluid Mech. 192, pp. 313-328 (1988).

M.Y. Louge \& J.T. Jenkins: "Development and Utilization of New Diagnostics for Dense-Phase Pneumitic Transport", 10 Quarterly Technical Progress Reports to the DOE (October 1, 1988 to March 31, 1990), Contract number: DE-AC22-88PC88947.

M. Louge, J. Jenkins \& M. Hopkins: "The relaxation of the second moments in rapid shear flows of smooth disks", Proceedings of the $2^{\text {nd }}$ USIJapan Conference on Micromechanics of Granular Materials, Clarkson University, August 1991.

\section{* Appendix}

Preprint of the paper by M. Louge, J. Jenkins \& M. Hopkins: "The relaxation of the second moments in rapid shear flows of smooth disks", Proceedings of the $2^{\text {nd }}$ US/Japan Conference on Micromechanics of Granular Materials, Clarkson University, August 1991.

*<smiles>CCCCOCCOCC1CC1</smiles><smiles>CCCCCCCCCCCCC</smiles><smiles>CC1CC1CCCC1(C)CC1</smiles>

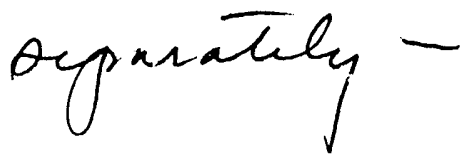

\section{DISCLAIMER}

This report was prepared as an account of work sponsored by an agency of the United States Government. Neither the United States Government nor any agency thereof, nor any of their makes any warranty, express or implied, or assumes any legal liability or responsibility for the accuracy, completeness, or usefulness of any information, apparatus, product, or

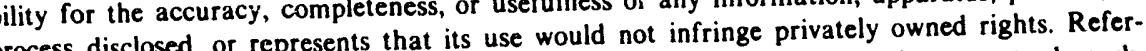
ence herein to any specific commercial product, process, or service by trade name, trademark, manufacturer, or otherwise does not necessarily constitute or imply its endorsement, recommendation, or favoring by the United Siates Government or any agency thereof. The views and opinions of authors expressed herein do not necessarily state or reflect those of the United States Government or any agency thereof. 

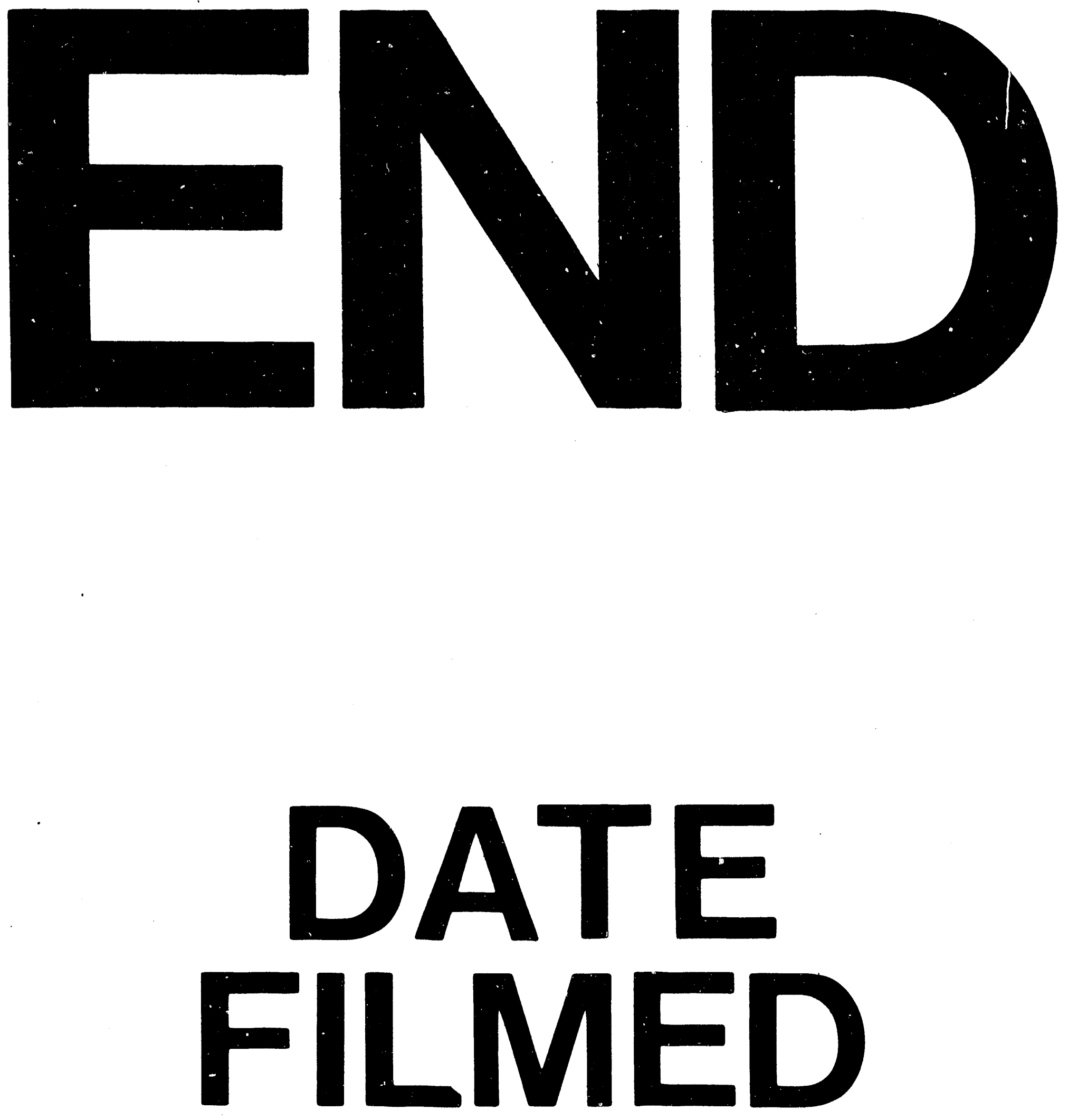

I

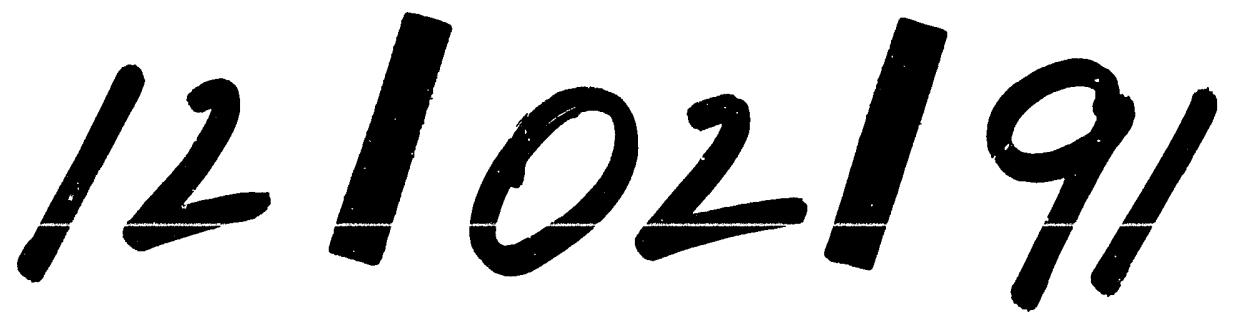


